\title{
Intravenous Topiramate: Pharmacokinetics in Dogs with Naturally Occurring Epilepsy
}

\author{
Irene Vuu 1,2, Lisa D. Coles ${ }^{1,2}$, Patricia Maglalang ${ }^{1,3}$, Ilo E. Leppik', ${ }^{2,4}$, Greg Worrell, \\ Daniel Crepeau ${ }^{5}$, Usha Mishra ${ }^{1}$, James C. Cloyd ${ }^{1,2}$ and Edward E. Patterson ${ }^{6 *}$
}

${ }^{1}$ Center for Orphan Drug Research, University of Minnesota, Minneapolis, MN, USA, ${ }^{2}$ Department of Experimental and Clinical Pharmacology, College of Pharmacy, University of Minnesota, Minneapolis, MN, USA, ${ }^{3}$ College of Science and Engineering, University of Minnesota, Minneapolis, MN, USA, ${ }^{4}$ UMP MINCEP Epilepsy Care, Minneapolis, MN, USA,

${ }^{5}$ Mayo Clinic, Rochester, MN, USA, ${ }^{6}$ College of Veterinary Medicine, University of Minnesota, Saint Paul, MN, USA

OPEN ACCESS

Edited by:

Sarah A. Moore,

Ohio State University, USA

Reviewed by:

Karen Munana,

North Carolina State University, USA

Sheila Carrera-Justiz,

University of Florida, USA

*Correspondence:

Edward E. Patterson

patte037@umn.edu

Specialty section:

This article was submitted to

Veterinary Neurology and

Neurosurgery,

a section of the journal

Frontiers in Veterinary Science

Received: 04 September 2016 Accepted: 15 November 2016 Published: 05 December 2016

Citation:

Vuu I, Coles LD, Maglalang $P$, Leppik IE, Worrell G, Crepeau D, Mishra U, Cloyd JC and Patterson EE

(2016) Intravenous Topiramate: Pharmacokinetics in Dogs with Naturally Occurring Epilepsy.

Front. Vet. Sci. 3:107. doi: 10.3389/fvets.2016.00107
Rationale: Barriers to developing treatments for human status epilepticus include the inadequacy of experimental animal models. In contrast, naturally occurring canine epilepsy is similar to the human condition and can serve as a platform to translate research from rodents to humans. The objectives of this study were to characterize the pharmacokinetics of an intravenous (IV) dose of topiramate (TPM) in dogs with epilepsy and evaluate its effect on intracranial electroencephalographic (iEEG) features.

Methods: Five dogs with naturally occurring epilepsy were used for this study. Three were getting at least one antiseizure drug as maintenance therapy including phenobarbital (PB). Four (ID 1-4) were used for the $10 \mathrm{mg} / \mathrm{kg}$ IV TPM + PO TPM study, and three (ID 3-5) were used for the $20 \mathrm{mg} / \mathrm{kg}$ IV TPM study. IV TPM was infused over $5 \mathrm{~min}$ at both doses. The animals were observed for vomiting, diarrhea, ataxia, and lethargy. Blood samples were collected at scheduled pre- and post-dose times. Plasma concentrations were measured using a validated high-performance liquid chromatography-mass spectrometry method. Non-compartmental and population compartmental modeling were performed (Phoenix WinNonLin and NLME) using plasma concentrations from all dogs in the study. iEEG was acquired in one dog. The difference between averaged iEEG energy levels at 15 min pre- and post-dose was assessed using a Kruskal-Wallis test.

Results: No adverse events were noted. TPM concentration-time profiles were best fit by a two compartment model. PB co-administration was associated with a 5.6-fold greater clearance and a 4-fold shorter elimination half-life. iEEG data showed that TPM produced a significant energy increase at frequencies $>4 \mathrm{~Hz}$ across all 16 electrodes within 15 min of dosing. Simulations suggested that dogs on an enzyme inducer would require $25 \mathrm{mg} / \mathrm{kg}$, while dogs on non-inducing drugs would need $20 \mathrm{mg} / \mathrm{kg}$ to attain the target concentration $(20-30 \mu \mathrm{g} / \mathrm{mL})$ at 30 min post-dose.

Conclusion: This study shows that IV TPM has a relatively rapid onset of action, loading doses appear safe, and the presence of PB necessitates a higher dose to attain targeted concentrations. Consequently, it is a good candidate for further evaluation for treatment of seizure emergencies in dogs and people.

Keywords: translational, dog, epilepsy, seizures, topiramate, ASD 


\section{INTRODUCTION}

Status epilepticus (SE) is defined as a condition characterized by abnormally prolonged seizures that can lead to long-term consequences, including permanent neuronal injury (1). SE has been reported to have an incidence between 2.5 and $59 \%$ in dogs with idiopathic epilepsy (2-4), and $32 \%$ in dogs with secondary epilepsy (3). In dogs that have had at least one episode of SE, overall mortality rates (primarily from euthanasia) were $32-38 \%$ $(2,5)$. In humans, SE occurs with an incidence between 0.04 and $0.06 \%$ in the United States, resulting in an overall mortality rate of $22 \%$ (6). While benzodiazepines are the standard first line of care for SE in both dogs and humans $(7,8)$, approximately onethird of humans fail to respond to first-line therapy (9). There remains a need for safe alternatives for early and rapid first- and/ or second-line therapy of SE to reduce the probability of recurring seizures, minimize associated complications, and improve patient outcomes.

One of the barriers to developing new treatments for $\mathrm{SE}$ is the experimental model used to find and evaluate investigational therapies. Oftentimes in rodent models, epilepsy is induced by chemical or electrical insult and may not be truly representative of epilepsy pathophysiology (10). Dogs with naturally occurring epilepsy have been proposed as appropriate models to examine new antiepileptic therapies prior to human trials (11). Canine epilepsy is strikingly similar to the human condition in both disease presentation and response to treatment. Holliday et al. demonstrated that intracranial electroencephalograms (EEGs) of dogs and humans during focal onset seizure are indistinguishable (12). Moreover, studies of antiseizure drugs (ASDs), such as fosphenytoin and levetiracetam, have shown comparable efficacy in both dogs and humans for SE $(11,13)$. Given these similarities, assessing new therapies for SE in dogs will facilitate drug development and increase the chance of successful translation for both canine and human SE.

Among the newer ASDs with injectable formulations, topiramate (TPM) is an attractive candidate for evaluation in the treatment of SE. TPM is the second-generation, broad-spectrum ASD that inhibits of voltage-gated sodium channels and enhances gamma-aminobutyrate (GABA) activity at specific $\mathrm{GABA}_{\mathrm{A}}$ receptor subtypes (14). TPM also has mechanisms of action that differ from those exhibited by current therapies, including antagonizing AMPA/kainate glutamate receptors, and inhibiting specific carbonic anhydrase isozymes. Specifically in rodent studies of SE and ischemia, TPM has exhibited neuroprotection $(15,16)$. There are also several clinical reports in which TPM suspensions administered in humans via nasogastric tube was associated with seizure cessation in refractory SE. In both adults and children as young as 4.5 months, plasma concentrations of $2-40 \mu \mathrm{g} / \mathrm{mL}$ were associated with resolution of refractory SE (17-23).

Our group has studied the pharmacokinetics (PK) of a novel intravenous (IV) TPM formulation in humans. However, the PK of IV TPM has not been characterized in dogs. Furthermore, while oral TPM might be useful in dogs, there is limited information on oral PK and no information in dogs with naturally occurring epilepsy on antiseizure medications (24). The aims of this study were to (1) characterize TPM PK following an IV and oral dose and (2) simulate doses to attain target concentrations of $20-30 \mu \mathrm{g} / \mathrm{mL}$, upper range of concentrations that have been associated with efficacy in humans. As an exploratory analysis, we also report the effect of IV TPM on intracranial electroencephalographic (iEEG) features in one dog.

\section{MATERIALS AND METHODS}

\section{Study Animals and Safety Monitoring}

Five dogs with naturally occurring epilepsy were used in this study. Three of the dogs have uncontrolled seizures despite being on antiseizure maintenance regimens. Approval was obtained through the Institutional Animal Care and Use Committee of the University of Minnesota prior to the initiation of the study. The dogs were housed at the University of Minnesota's Veterinary College. Each dog was previously implanted with a device which wirelessly transmits iEEG recordings $(25,26)$. Dogs were monitored throughout the study for vomiting, diarrhea, and lethargy prior to and for $90 \mathrm{~min}$ after drug administration, and at each blood sampling time. In the event of a seizure emergency (seizure lasting $>5 \mathrm{~min}$ ) or repetitive seizures $(2+$ seizures within $1 \mathrm{~h}$, or $3+$ seizures within $4 \mathrm{~h}$ ), the on call veterinarian received an automated text message and confirmed the seizure activity using remote video monitoring. The rescue therapy protocol consisted of midazolam $12 \mathrm{mg}$ administered as a single intramuscular dose.

\section{Study Drug}

For this study, a stable isotope-labeled TPM compound containing $\operatorname{six}{ }^{13} \mathrm{C}$, resulting in a mass $6 \mathrm{U}$ greater than the unlabeled molecule was used for the IV formulation $(10 \mathrm{mg} / \mathrm{mL}$ in $10 \%$ Captisol $^{\circledR}$ ). This formulation was manufactured by the University of Iowa under Good Manufacturing Practices and has been licensed to Ligand/CuRx Pharmaceuticals. Unlabeled TPM tablets $(25 \mathrm{mg})$ purchased from the University of Minnesota Veterinary Pharmacy (Cipla USA, Inc.) were used for the oral treatment arm. Using a labeled IV formulation and non-labeled oral tablets allowed us to simultaneously administer both formulations and characterize TPM PK by each route. This approach also reduces interoccasion variability caused by dosing on different days and/ or times (27).

\section{Dose Rationale}

Based on reports of doses associated with efficacy in human SE $(2-40 \mu \mathrm{g} / \mathrm{mL})$, we aimed for a plasma TPM concentration on the higher end of the range $(20-30 \mu \mathrm{g} / \mathrm{mL})$ for a higher likelihood of efficacy without risking safety (17-23). A previous single IV dose study in one dog reported TPM concentrations from which we calculated an apparent volume of distribution (Vd) of $0.6 \mathrm{~L} / \mathrm{kg}(24)$. Using this $\mathrm{Vd}$, we estimated that IV doses of 10 and $20 \mathrm{mg} / \mathrm{kg}$ would produce initial concentrations $\left(\mathrm{C}_{0}\right)$ of $\sim 16$ and $32 \mu \mathrm{g} / \mathrm{mL}$, respectively.

\section{Study Design}

For low dose IV/oral TPM study, four dogs were used in this study (ID 1-4; Table 1). Two of the four dogs were on ASD maintenance 
TABLE 1 | Animal demographics at time of study.

\begin{tabular}{|c|c|c|c|c|c|c|c|}
\hline Subject & $\begin{array}{c}\text { Age } \\
\text { (years) }\end{array}$ & Gender & $\begin{array}{l}\text { Weight } \\
\text { (kg) }\end{array}$ & Breed & Seizure type & Seizure frequency & Co-medications \\
\hline 1 & 5 & $\begin{array}{l}\text { Male, } \\
\text { intact }\end{array}$ & 33 & $\begin{array}{l}\text { Coonhound } \\
\text { mix }\end{array}$ & $\begin{array}{l}\text { Focal, with } \\
\text { generalized seizures }\end{array}$ & $\begin{array}{l}\text { Generalized cluster seizures once every } \\
3 \text { weeks }\end{array}$ & $\begin{array}{l}\text { Levetiracetam, } \\
\text { zonisamide, phenobarbital }\end{array}$ \\
\hline 2 & 9 & $\begin{array}{l}\text { Male, } \\
\text { neutered }\end{array}$ & 29 & $\begin{array}{l}\text { Labrador } \\
\text { retriever mix }\end{array}$ & $\begin{array}{l}\text { Focal, with } \\
\text { generalized seizures }\end{array}$ & $\begin{array}{l}\text { Focal cluster seizures every } 2-4 \text { days. } \\
\text { With secondarily generalized cluster } \\
\text { seizures every } 1-2 \text { weeks }\end{array}$ & $\begin{array}{l}\text { Levetiracetam, } \\
\text { zonisamide, } \\
\text { phenobarbital, potassium } \\
\text { bromide }\end{array}$ \\
\hline 3 & 3 & $\begin{array}{l}\text { Male, } \\
\text { intact }\end{array}$ & 15 & Beagle & $\mathrm{N} / \mathrm{A}$ & $\begin{array}{l}\text { Seizure-free and in remission for } 2 \text { years } \\
\text { (had one witnessed generalized seizure) }\end{array}$ & $\mathrm{N} / \mathrm{A}$ \\
\hline 4 & 5 & $\begin{array}{l}\text { Female, } \\
\text { spayed }\end{array}$ & 29 & $\begin{array}{l}\text { Coonhound } \\
\text { mix }\end{array}$ & $\mathrm{N} / \mathrm{A}$ & $\begin{array}{l}\text { Seizure-free for and in remission } 2.5 \text { years } \\
\text { (had one witnessed generalized seizure) }\end{array}$ & $\mathrm{N} / \mathrm{A}$ \\
\hline 5 & 5 & $\begin{array}{l}\text { Male, } \\
\text { intact }\end{array}$ & 35 & $\begin{array}{l}\text { Coonhound } \\
\operatorname{mix}\end{array}$ & $\begin{array}{l}\text { Focal, with secondary } \\
\text { generalized seizures }\end{array}$ & $\begin{array}{l}\text { Single generalized seizures once every } \\
2-3 \text { months }\end{array}$ & Phenobarbital \\
\hline
\end{tabular}

regimen including phenobarbital (PB). Each dog was fasted overnight prior to receiving a $10 \mathrm{mg} / \mathrm{kg}$ dose of stable-labeled IV TPM infused over $5 \mathrm{~min}$. One hour following the IV bolus, each dog also received a $5 \mathrm{mg} / \mathrm{kg}$ dose of unlabeled oral TPM. This delay in oral administration was by design to allow evaluation of the IV dose on iEEG for $1 \mathrm{~h}$ after dosing. Each dog was fed no sooner than $2 \mathrm{~h}$ after the oral dose. Blood samples $(\sim 5 \mathrm{~mL})$ were collected from an indwelling catheter prior to dosing and at $0.083,0.25,0.5$, $0.75,1,1.5,2,2.5,3,4,6,8$, and $9 \mathrm{~h}$ following the IV bolus.

\section{High-Dose IV TPM Study}

Three dogs were used in this study (ID 3-5; Table 1). One dog was on PB maintenance therapy. Each dog was fasted overnight prior to receiving a $20 \mathrm{mg} / \mathrm{kg}$ dose of stable-labeled IV TPM infused over $5 \mathrm{~min}$. Blood samples $(\sim 5 \mathrm{~mL})$ were collected from an indwelling catheter prior to dosing and at $0.083,0.25,0.5,0.75$, $1,1.5,2,2.5,3,4,6,8$, and $9 \mathrm{~h}$ following the IV bolus.

\section{Diazepam Positive Control}

Intravenous diazepam (DZP) $(0.5 \mathrm{mg} / \mathrm{kg})$ was administered to two dogs that were having uncontrolled seizures (ID 1 and 2) during an interictal period as a positive control as it has been shown to elicit iEEG change.

\section{TPM Plasma Measurements}

Upon sample collection, blood was placed on ice, and plasma was separated. All samples were immediately frozen $\left(-20^{\circ} \mathrm{C}\right)$ until analysis. A high-performance liquid chromatography-mass spectrometry (HPLC-MS) method developed and validated at the Center for Orphan Drug Research was used to measure TPM concentrations in dog plasma. Seven calibration standards (run in triplicate) and nine quality control standards (low, medium, and high run in triplicates) were prepared in plasma. Study, calibration, and quality control samples $(250 \mu \mathrm{L})$ were extracted using methyl tert-butyl ether. TPM and stable-labeled TPM were analyzed using the Hewlett Packard Agilent 1100 Model G1946 liquid chromatography mass spectrometry detection system and Agilent ChemStation software. The analytes were separated using a Zorbax C18 column $(150 \mathrm{~mm} \times 3.0 \mathrm{~mm}, 3 \mu \mathrm{m})$, and the mobile phase consisted of an ammonium acetate buffer and methanol. The quantization was performed using the selective ion monitoring in the negative mode, with deuterated TPM (d10) as the internal standard. The mass-to-charge ratios were 338 and $244 \mathrm{~m} / z$ for TPM and stable-labeled TPM, respectively. The calibration curves were linear $\left(r^{2}=0.998\right)$ in the concentration range of $0.05-50 \mu \mathrm{g} / \mathrm{mL}$ for stable-labeled TPM and $0.05-10 \mu \mathrm{g} / \mathrm{mL}$ for TPM in plasma. The limit of detection and quantitation was $0.05 \mathrm{ng} / \mathrm{mL}$ and $0.05 \mu \mathrm{g} / \mathrm{mL}$, respectively. The precision for both TPM and stable-labeled TPM ranged from 3 to $6 \%$, and accuracy values were between 95 and $114 \%$ and 86 and 105\%, respectively.

\section{Pharmacokinetic Analysis}

Topiramate concentration-time data were analyzed using non-compartmental analysis (Phoenix WinNonLin, version 6.4, Pharsight Corporation, Mountain View, CA, USA). Pharmacokinetic parameter values included maximum concentration $\left(C_{\max }\right)$, time at which maximum concentration is achieved $\left(t_{\max }\right)$, elimination rate half-life $\left(t_{1 / 2}\right)$, and the area under the time-concentration curve $\left(\mathrm{AUC}_{\mathrm{INF}}\right)$ calculated using the equation $\mathrm{AUC}=\int_{t=0}^{t=\infty} \mathrm{Cp} \times d t$ (where $\mathrm{Cp}$ is the plasma TPM concentration) and a linear-log trapezoidal method. Oral bioavailability (F\%) was calculated using the equation $\mathrm{F}(\%)=\frac{\mathrm{AUC}(\text { oral }) \times \operatorname{Dose}(\mathrm{IV})}{\mathrm{AUC}(\mathrm{IV}) \times \operatorname{Dose}(\text { oral })} \times 100$. Clearance $(\mathrm{CL})$ and $\mathrm{Vd}$ were calculated using the equations $\mathrm{CL}=\frac{\text { Dose } \times \mathrm{F}}{\mathrm{AUC}}$ and $\mathrm{CL}=k_{e} \times \mathrm{Vd}$, respectively, where $k_{e}$ is the elimination rate constant. Concentration-time profiles were created using the GraphPad Prism 7 (Version 7.0a, GraphPad Software, Inc., La Jolla, CA, USA).

Pharmacokinetics parameters were also determined using population compartmental modeling (Phoenix Non-Linear Mixed Effects software, version 1.3, Pharsight Corporation, Mountain View, CA, USA). First-order conditional estimation extended least squares method was used throughout the model building process. One and two compartment models were evaluated. A proportional error model for between subject variability was used. Both additive and multiplicative error models for residual variability were evaluated. The best fit model was determined using visual inspection, goodness of fit plots, weighted residual 
plots, weighted sum of squared residuals, Akaike's Information Criterion, and precision of model parameters.

The presence of a CYP3A4-inducing co-medication (such as $\mathrm{PB}$ ) was evaluated as a covariate for its influence on TPM clearance. The relationship of the covariate and TPM clearance was modeled by the equation $\mathrm{Cl}=\mathrm{tvCl} \times e^{\mathrm{dCl}} \times e^{\eta \mathrm{Cl}}$, where $\mathrm{Cl}$ is the clearance from the central compartment, $\mathrm{tvCl}$ is the typical value of the clearance from the population, $\mathrm{dCl}$ is the estimated value of the inducer effect, and $\eta \mathrm{Cl}$ is the between-subject variability (BSV) of clearance. A covariate was considered statistically significant if inclusion of the covariate resulted in a decrease in the objective function value (OFV) of at least $6.64\left(p<0.01, x^{2}\right.$, degree of freedom $=1$ ). The final model was used to simulate of 5-, 10-, and 15-min infusions IV TPM at doses ranging from 10 to $30 \mathrm{mg} / \mathrm{kg}$.

\section{Electroencephalographic Analysis}

Intracranial electroencephalographic analysis was performed in one dog (ID 3) that was not having uncontrolled seizures (not on co-medications). Sixteen electrode channels were continuously sampled at $399.6 \mathrm{~Hz}$. A bandpass filter was applied to create six frequency bands: delta $(1-4 \mathrm{~Hz})$, theta $(4-8 \mathrm{~Hz})$, alpha $(8-12 \mathrm{~Hz})$, beta $(12-25 \mathrm{~Hz})$, low gamma $(25-40 \mathrm{~Hz})$, and high gamma $(40-120 \mathrm{~Hz})$. In order to evaluate differences in EEG features, energy of each electrode within each frequency band was calculated in 1-s intervals by summing the square of the EEG signal amplitude within the 1-s window. The average energy level was calculated for three 15-min ranges: starting from 15-min pre-dose to dosing, from dosing to 15 -min postdose, and from 15-min post-dose to 30 -min post-dose. The difference between averaged energy levels at pre-dose and each post-dose interval were calculated. $p$ Values were generated by the Kruskal-Wallis test comparing the averaged energy level from pre-dose to the two averaged energy levels post-dose. While EEG systems were implanted in all dogs, EEG data were not attained for all animals due to electrical malfunctioning of the electrodes and/or data cards as some of the devices had been implanted for up to 5 years.

\section{RESULTS}

\section{Demographics and Adverse Events}

Demographics of the dogs are represented in Table 1. No adverse events were observed for either dose group throughout the course of the study.

\section{Non-Compartmental PK Analysis}

The concentration-time profiles of plasma ${ }^{13} \mathrm{C}$-TPM following the low- and high-dose IV infusions are shown in Figure 1. Pharmacokinetic parameter estimates using non-compartmental analysis are summarized in Table 2. TPM clearance was greater and elimination half-life shorter in dogs receiving chronic $\mathrm{PB}$. The clearance was $0.5-0.7$ versus $0.1 \mathrm{~L} / \mathrm{h} / \mathrm{kg}$ and elimination half-life $0.5-1$ versus $3.7-5 \mathrm{~h}$ in dogs with and without $\mathrm{PB}$, respectively, suggesting hepatic enzyme induction by PB. Clearance, volume of distribution, and elimination half-life were similar for both dose
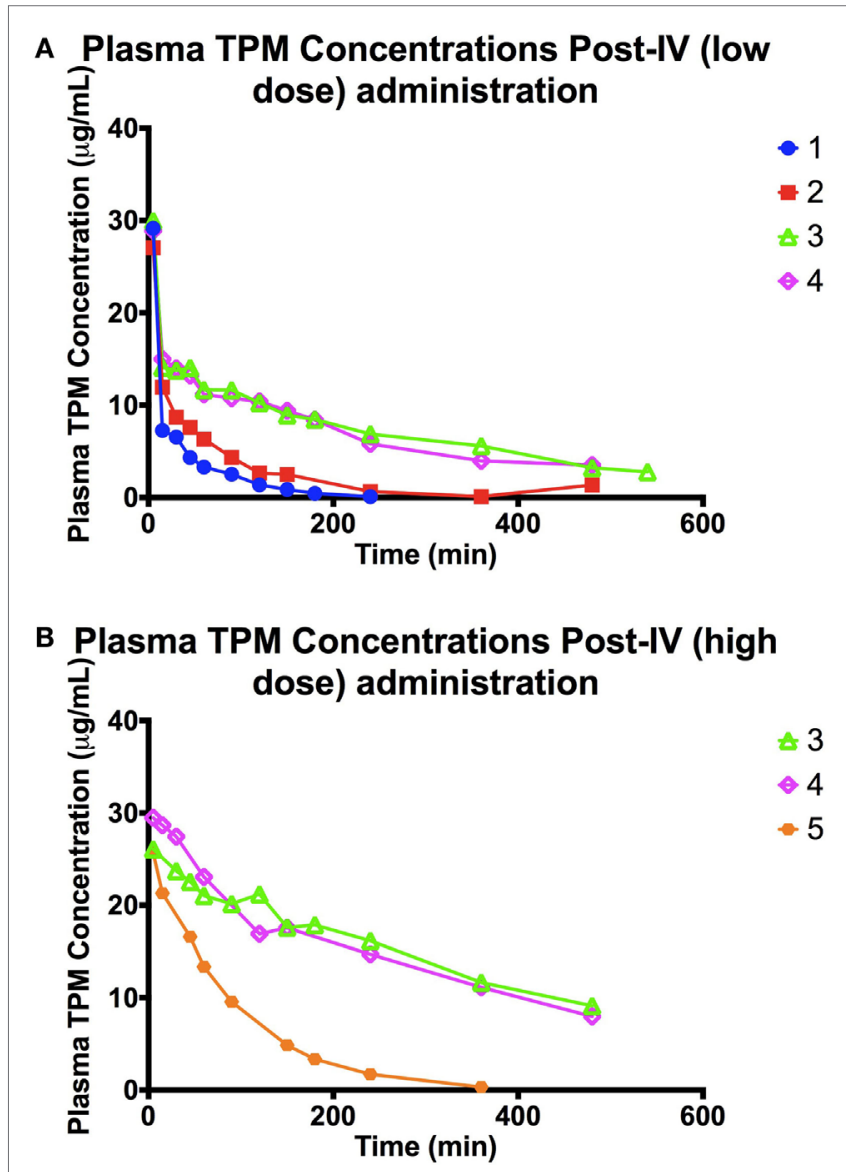

FIGURE 1 | (A) Plasma TPM concentration time profile following an intravenous bolus (low dose: $10 \mathrm{mg} / \mathrm{kg}$ ) of stable-labeled TPM. (B) Plasma TPM concentration time profile following an intravenous bolus (high dose: $20 \mathrm{mg} / \mathrm{kg}$ ) of stable-labeled TPM.

groups studied. $\mathrm{AUC}_{\mathrm{INF}}$ approximately doubled as dose doubled suggesting dose-proportional PK.

Plasma TPM concentration-time profiles following oral administration are depicted in Figure 2. $C_{\max }$ following oral administration ranged between 1.9 and $2 \mu \mathrm{g} / \mathrm{mL}$ at $1-1.5 \mathrm{~h}\left(T_{\max }\right)$, with a $t_{1 / 2}$ between 1.7 and $2 \mathrm{~h}$ in the two dogs on PHB. In the two dogs not on $\mathrm{PB}$, a $C_{\max }$ of $4.7-5.5 \mu \mathrm{g} / \mathrm{mL}$ at $0.5-1 \mathrm{~h}$ was observed, with a $t_{1 / 2}$ of $4 \mathrm{~h}$. Individual oral bioavailability ranged between 61 and $102 \%$. These results are summarized in Table 3. Similar to the IV administration, the two dogs on PHB exhibited higher clearance rates, and consequently, shorter half-lives compared to the two dogs not on PB.

\section{Compartmental PK Analysis}

A two compartment model with first-order elimination best fit the TPM concentration data following IV administration (Figure S1 in Supplementary Material). Parameter estimates are provided in Table S1 in Supplementary Material. A systematic bias in clearance based on dose was observed. The inclusion of whether the dog was on an enzyme-inducing co-medication as a covariate resulted in a decrease in the OFV from the base model 
TABLE 2 | Pharmacokinetic parameter values estimated from non-compartmental analysis after an intravenous bolus of stable-labeled TPM.

\begin{tabular}{|c|c|c|c|c|c|c|}
\hline ID & Group & $t_{1 / 2}(h)$ & $C_{1}(\mu \mathrm{g} / \mathrm{mL})$ & AUC $_{\mathrm{INF} \_ \text {obs }}(\mu \mathrm{g} \times \mathrm{h} / \mathrm{mL})$ & V_obs (L/kg) & Cl_obs (L/h/kg) \\
\hline 1 & LOW & 0.47 & 29.2 & 13.7 & 0.50 & 0.73 \\
\hline 2 & LOW & 0.75 & 27.1 & 20.6 & 0.53 & 0.49 \\
\hline 3 & LOW & 3.71 & 30 & 83.5 & 0.64 & 0.12 \\
\hline 4 & LOW & 4.05 & 28.9 & 101 & 0.58 & 0.1 \\
\hline 3 & $\mathrm{HIGH}$ & 4.99 & 26.1 & 194 & 0.74 & 0.1 \\
\hline 4 & $\mathrm{HIGH}$ & 4.52 & 29.5 & 176 & 0.74 & 0.11 \\
\hline 5 & $\mathrm{HIGH}$ & 0.95 & 25.7 & 38.4 & 0.71 & 0.52 \\
\hline
\end{tabular}

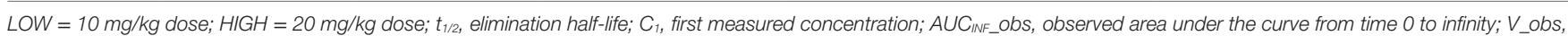
observed volume of distribution; Cl_obs, observed clearance.

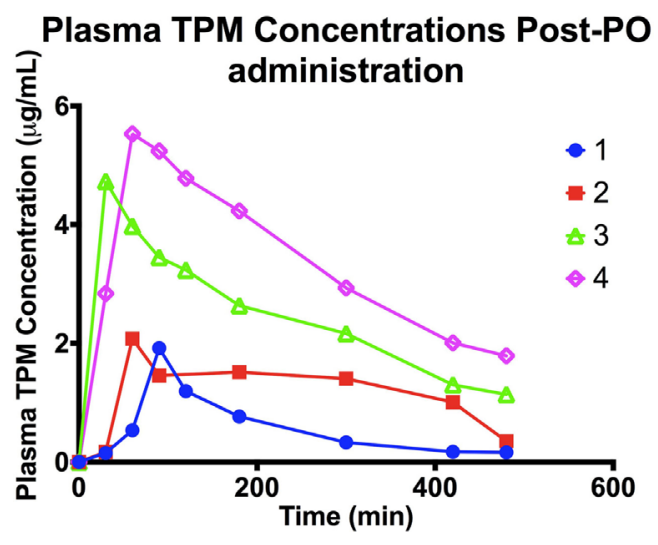

FIGURE 2 | Plasma TPM concentration time profile following an oral dose $(5 \mathrm{mg} / \mathrm{kg})$ of TPM.

(difference in OFV $=25$ ) and an improvement in the goodness of fit plots and precision of parameter estimates. Therefore, the effect of an enzyme inducer on clearance was included in the final model. The presence of PB is estimated to affect TPM clearance by a factor of 5.64. Except for peripheral compartment clearance, all model-fitted parameters were estimated with good precision with all coefficients of variation below 25\%. A multiplicative error model best described the residual error with an estimate of $15 \%$, which is consistent with analytical error. Visual predictive check plots (Figure S2 in Supplementary Material) illustrated the observed data percentiles fall within the $90 \%$ (5-95\%) model-predicted intervals.

\section{Simulation Analysis}

Using the final model above, various infusion rates and doses were simulated (Figure 3). For dogs not on enzyme-inducing comedications, simulated time-concentration profiles suggest that a 5-min infusion of $20 \mathrm{mg} / \mathrm{kg}$ would achieve target concentration range of $20-30 \mu \mathrm{g} / \mathrm{mL}$ at $30 \mathrm{~min}$ post-dose. However, in dogs on enzyme-inducing co-medications, a dose between 25 and $30 \mathrm{mg} /$ $\mathrm{kg}$ infused over $5 \mathrm{~min}$ would be required to attain the same target range.

\section{EEG Analysis}

In one dog (ID 3), IV TPM produced EEG changes shortly after the infusion, which continued in the subsequent $40-60 \mathrm{~min}$
(Figure S3 in Supplementary Material). Statistically significant positive energy differences in all 6 frequency bands across all 16 channels were seen comparing the pre-dose time ( $-15-0 \mathrm{~min})$ to both post-dose times (0-15 $\mathrm{min}$ and 15-30 $\mathrm{min}$ ) (Table S2 in Supplementary Material). Detailed energy differences across the 6 frequency bands in each of the 16 channels comparing the pre-dose time to $0-15$ min post-dose are shown in Table S3 in Supplementary Material.

\section{DISCUSSION}

This study is unique in that it evaluated the PK of IV and oral TPM in dogs with naturally occurring epilepsy. This is also the first study that reports the absolute bioavailability of oral TPM and the effect of PB on TPM PK in dogs. The oral bioavailability was $62-102 \%$ that is similar to what has been reported in humans (28). Furthermore, enzyme induction increases TPM clearance in both humans and dogs. In humans, enzyme-inducing comedications such as carbamazepine and phenytoin showed a 1.5fold increase in TPM clearance. In our study, PB increased TPM clearance by 5.6-fold. To explain this discrepancy, Caldwell et al. found that while $82 \%$ of TPM is excreted unchanged in the urine in humans, only $28 \%$ is excreted unchanged in dogs (29). PB is a known inducer of CYP 3A4, the major enzyme responsible for TPM metabolism. A recent study evaluating the effects of chronic administration of $\mathrm{PB}$ on the $\mathrm{PK}$ of levetiracetam in dogs with epilepsy found similar results (30). Potential drug-drug interactions should be taken into consideration when dosing TPM in both dogs and humans. Dose adjustments are likely needed when TPM is used in conjunction with chronic enzyme-inducing or enzyme-inhibiting co-medications in dogs. Although two of the dogs on maintenance ASDs were also taking zonisamide and levetiracetam, and these drugs are not known inducers or inhibitors of TPM metabolism.

A limitation of this study is the small number of animals as is the heterogeneity among the dogs. However, we think our animals are more representative of the true population and allow us to preliminarily explore the effects of co-administered ASDs on TPM PK. Although our population model is based on a small number of animals, it provides useful information. We based this assertion on prior study, we did with four dogs. Using pharmacokinetic data and simulations, we were able to predict phenytoin exposure from different fosphenytoin dosing strategies and determine the optimal dosing regimen to attain the 
TABLE 3 | Pharmacokinetic parameter values estimated from non-compartmental analysis after an oral dose (5 mg/kg) of unlabeled TPM.

\begin{tabular}{|c|c|c|c|c|c|c|c|}
\hline ID & $t_{1 / 2}(h)$ & $T_{\max }(\min )$ & $C_{\max }(\mu \mathrm{g} / \mathrm{mL})$ & AUC $_{\mathrm{INF}-\text { obs }}(\mu \mathrm{g} \times \mathrm{h} / \mathrm{mL})$ & V_obs (L/kg) & Cl_obs (L/h/kg) & $\mathbf{F}(\%)$ \\
\hline 1 & 2.02 & 90 & 1.92 & 4.73 & 2.13 & 0.73 & 69.2 \\
\hline 2 & 1.66 & 60 & 2.08 & 10.5 & 1.16 & 0.49 & 102 \\
\hline 3 & 3.98 & 30 & 4.73 & 25.7 & 0.69 & 0.12 & 61.7 \\
\hline 4 & 4.08 & 60 & 5.53 & 36.9 & 0.58 & 0.1 & 73.0 \\
\hline
\end{tabular}

Volume and clearance were adjusted for bioavailability.

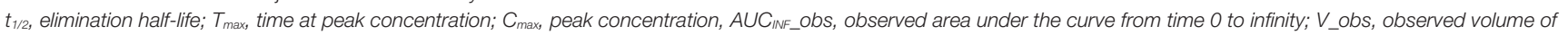
distribution; Cl_obs, observed clearance; F, bioavailability.

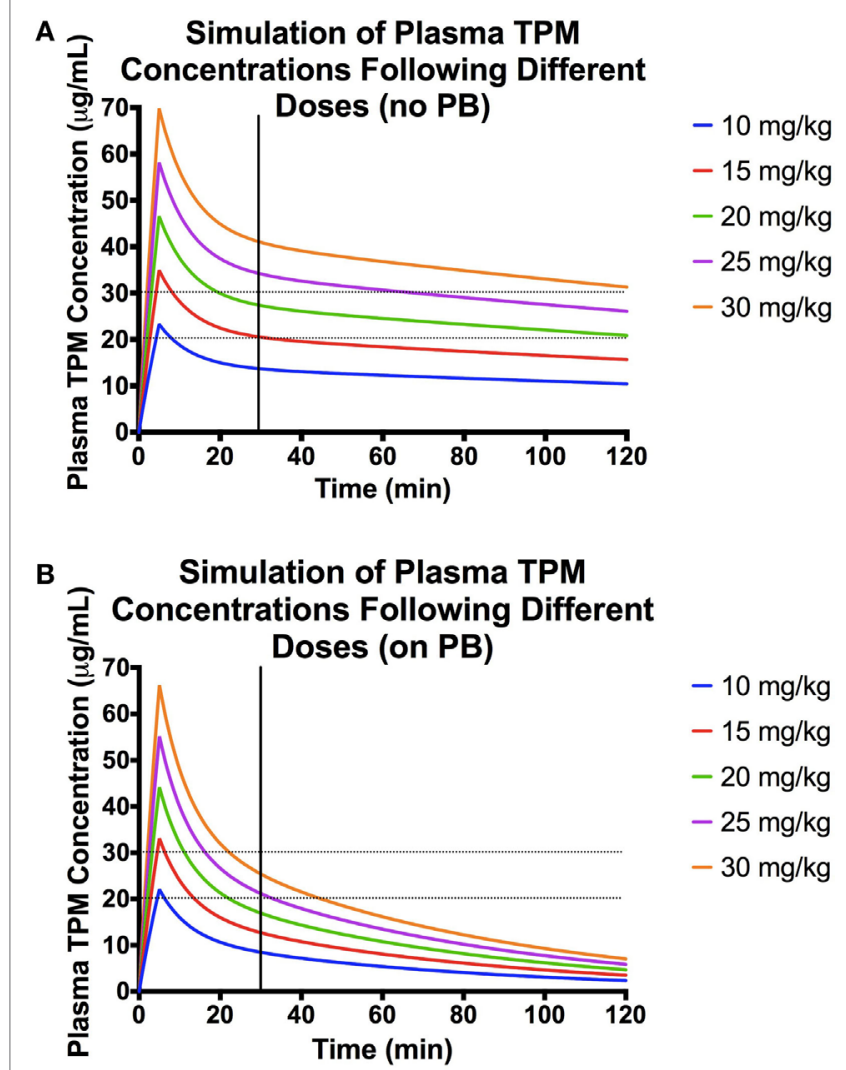

FIGURE 3 | Population pharmacokinetic parameters used for the simulations: volume of distribution (Vd) of central compartment $=$ $376 \mathrm{~mL} / \mathrm{kg}$, Vd of peripheral compartment $=298 \mathrm{~mL} / \mathrm{kg}$, clearance (CL) from central compartment $=1.84 \mathrm{mg} /(\mathrm{kg} \times \mathrm{min}), \mathrm{CL}$ from peripheral compartment $=21 \mathrm{~mL} /(\mathrm{kg} \times \mathrm{min})$, and effect of $\mathrm{PB}$ presence on $\mathrm{CL}=\mathbf{1 . 7 3}$. (A) Simulations of plasma concentration-time profiles following 5-min infusions of different doses in a dog not on enzyme-inducing co-medications. Here, the desired range is represented by the black dashed lines, and the black vertical line denotes 30 min post-dose. (B) Simulations of plasma concentration-time profiles following 5-min infusions of different doses in a dog on enzyme-inducing co-medications. Here, the desired range is represented by the black dashed lines, and the black vertical line denotes 30 min post-dose.

same phenytoin concentrations that are considered therapeutic in human SE in dogs (11). We subsequently used that dosing regimen to attain the targeted phenytoin concentration in a randomized safety and efficacy clinical trial (31). Based on case reports of TPM oral suspensions used to treat refractory SE, our goal target concentration range was $20-30 \mu \mathrm{g} / \mathrm{mL}$. Our simulations suggest that these doses should be used in designing future a clinical trial in canine SE. Further evidence of the appropriateness of the population model is that the precision of the model parameters, and other goodness of fit criteria did not show any major model misspecifications.

Although we were only able to assess iEEG in one dog, the significant changes between pre-dose EEG energy levels and those up to $30 \mathrm{~min}$ after IV TPM administration suggest sufficient diffusion into the brain. This observation warrants further study in additional animals. Benzodiazepines in both rodent and dog model show significant increases in energy in frequencies greater than $4 \mathrm{~Hz}$ and decreases in delta frequency energy, as we saw in this one dog. These observations suggest IV TPM may be beneficial for the treatment of SE.

In conclusion, IV TPM doses of 10 and $20 \mathrm{mg} / \mathrm{kg}$ infused over 5 min were shown to be safe and tolerable in dogs. Concurrent administration of PB increased the clearance of TPM 5.6-fold. Simulations suggest that doses of 20 and $25 \mathrm{mg} / \mathrm{kg}$ of IV TPM are necessary to achieve a target concentration between 20 and $30 \mu \mathrm{g} / \mathrm{mL}$ in dogs not on $\mathrm{PB}$ and dogs on $\mathrm{PB}$, respectively. A key strength of this study is the use of animals with naturally occurring epilepsy. The results of this study provide information on optimizing TPM therapy for future studies of canine SE, which will subsequently guide the design of IV TPM clinical trials of human SE. Future work includes conducting a phase II/III efficacy study in canine SE using the dose strategy determined from the PK modeling results of this study.

\section{AUTHOR CONTRIBUTIONS}

IV, LC, PM, IL, GW, JC, and EP designed the study and revised drafts of the manuscript. IV, LC, and PM conducted the study, collected samples, performed data analysis, interpreted data, prepared the initial drafts of the manuscript, and performed final edits. UM developed the TPM assay and analyzed samples. DC performed the statistical analysis of iEEG data and revised drafts of the manuscript. EP also supervised the care of the animals.

\section{ACKNOWLEDGMENTS}

The authors would like to acknowledge the American Kennel Club Canine Health Foundation Grant \#2133, NIH/NINDS R21-NS072166, and NIH U01-NS073557 (GW) which funded this research. The authors also acknowledge and thank Andrea Eckert for her care of the animals and sample collection. 


\section{SUPPLEMENTARY MATERIAL}

The Supplementary Material for this article can be found online at http://journal.frontiersin.org/article/10.3389/fvets.2016.00107/ full\#supplementary-material.

FIGURE S1 | (A) Observed versus individual predicted concentrations derived from the two compartment model using a population approach. (B) Observed versus population predicted concentrations derived from the two compartment model using a population approach.

FIGURE S2 | (A) Visual predictive check of the population two compartment model following an intravenous bolus of TPM for a dog not on inducing co-medications. Here, the observed quantiles (red lines) are superimposed with the predictive check quantiles (black lines) over the observed data (blue circles). (B) Visual predictive check of the population two compartment model following an intravenous bolus of TPM for a dog on inducing co-medications. Here, the observed quantiles (red lines) are

\section{REFERENCES}

1. Trinka E, Cock H, Hesdorffer D, Rossetti AO, Scheffer IE, Shinnar S, et al. A definition and classification of status epilepticus - report of the ILAE task force on classification of status epilepticus. Epilepsia (2015) 56(10):1515-23. doi:10.1111/epi.13121

2. Saito M, Muñana KR, Sharp NJH, Olby NJ. Risk factors for development of status epilepticus in dogs with idiopathic epilepsy and effects of status epilepticus on outcome and survival time: 32 cases (1990-1996). J Am Vet Med Assoc (2001) 219(5):618-23. doi:10.2460/javma.2001.219.618

3. Platt SR, Haag M. Canine status epilepticus: a retrospective study of 50 cases. J Small Anim Pract (2002) 43:151-3. doi:10.1111/j.1748-5827.2002. tb00047.x

4. Monteiro R, Adams V, Keys D, Platt SR. Canine idiopathic epilepsy: prevalence, risk factors and outcome associated with cluster seizures and status epilepticus. J Small Anim Pract (2012) 53:526-30. doi:10.1111/j.1748-5827. 2012.01251.x

5. Zimmerman R, Hülsmeyer V-I, Sauter-Louis C, Fischer A. Status epilepticus and epileptic seizures in dogs. J Vet Intern Med (2009) 23:970-6. doi:10.1111/j.1939-1676.2009.0368.x

6. DeLorenzo RJ, Pellock JM, Towne AR, Boggs JG. Epidemiology of status epilepticus. J Clin Neurophys (1995) 12(4):316-25. doi:10.1097/00004691199512040-00003

7. Podell M. Antiepileptic drug therapy. Clin Tech Small Anim Pract (1998) 13(3):185-92. doi:10.1016/S1096-2867(98)80040-6

8. Brophy GM, Bell R, Claassen J, Alldredge B, Bleck TP, Glauser T, et al. Guidelines for the evaluation and management of status epilepticus. Neurocrit Care (2012) 17:3-23. doi:10.1007/s12028-012-9695-z

9. Hocker SE, Britton JW, Mandrekar JN, Wijdicks EF, Rabinstein AA. Predictors of outcomes in refractory status epilepticus. J Am Med Assoc Neurol (2013) 70(1):72-7. doi:10.1001/jamaneurol.2013.578

10. Pitkänen A, McIntosh T. Animal models of post-traumatic epilepsy. J Neurotrauma (2006) 23(2):241-61. doi:10.1089/neu.2006.23.241

11. Coles LD, Leppik IE, Patterson EE, Rivers Z, Mishra U, Cloyd JC. Use of IV fosphenytoin pharmacokinetics to determine the loading dose for a clinical trial of canine status epilepticus. Epilepsia (2015) 56(6):888-94. doi:10.1111/ epi.12961

12. Holliday TA, Cunningham JG, Gutnick MJ. Comparative clinical and electroencephalographic studies of canine epilepsy. Epilepsia (1970) 11:281-92. doi:10.1111/j.1528-1157.1970.tb03892.x

13. Hardy BT, Patterson EE, Cloyd JC, Hardy RM, Leppik IE. Double-masked, placebo-controlled study of intravenous levetiracetam for the treatment of status epilepticus and acute repetitive seizures in dogs. J Vet Intern Med (2012) 26:334-40. doi:10.1111/j.1939-1676.2011.00868.x

14. Topiramate (Tablet) Package Insert. Miami, FL: Cipla USA Inc. (2015).

15. Niebauer M, Gruenthal M. Topiramate reduces neuronal injury after experimental status epilepticus. Brain Res (1999) 837:263-9. doi:10.1016/ S0006-8993(99)01615-7 superimposed with the predictive check quantiles (black lines) over the observed data (blue circles).

FIGURE S3 | Electroencephalograph normalized signals from beta and low gamma frequency bands averaged over 1-min intervals in one dog

TABLE S1 | Pharmacokinetic parameter estimates estimated from a population two compartment analysis following an intravenous bolus of TPM, pooling together low- and high-dose data. tVV, typical value of volume of distribution from central compartment; tvCl, typical value of clearance from central compartment; dCl, effect of PB presence on Cl; BSV, between-subject variability; CV\%, coefficient of variation; RSE\%, relative standard error.

TABLE S2 | Difference between energy levels averaged across each frequency band. An asterisk (*) denotes the differences were statistically significant across all channels.

TABLE S3 | Differences between the averaged energy levels at $15 \mathrm{~min}$ pre-dose (-15 to $0 \mathrm{~min}$ ) and $15 \mathrm{~min}$ post-dose $(0$ to $+15 \mathrm{~min})$ and their $p$-value (probability of having a difference that large or more extreme).

16. Yang Y, Shuaib A, Li Q, Siddiqui MM. Neuroprotection by delayed administration of topiramate in middle cerebral artery embolization. Brain Res (1998) 804:169-76. doi:10.1016/S0165-3806(97)00211-3

17. Blumkin L, Lerman-Sagie T, Houri T, Gilad E, Nissenkorn A, Ginsberg M, et al. Pediatric refractory partial status epilepticus responsive to topiramate. J Child Neurol (2005) 20:239-41. doi:10.1177/08830738050200031701

18. Akylidiz BN, Kumandas S. Treatment of pediatric refractory status epilepticus with topiramate. Childs Nerv Syst (2011) 27:1425-30. doi:10.1007/ s00381-011-1432-y

19. Perry MS, Holt PJ, Sladky JT. Topiramate loading for refractory status epilepticus in children. Epilepsia (2006) 47(6):1070-1. doi:10.1111/j.15281167.2006.00564.x

20. Kahriman M, Minecan D, Kutluay E, Selwa L, Beydoun A. Efficacy of topiramate in children with refractory status epilepticus. Epilepsia (2003) 44(10):1353-6. doi:10.1046/j.1528-1157.2003.11803.x

21. Towne AR, Garnett LK, Waterhouse EJ, Morton LD, DeLorenzo RJ. The use of topiramate in refractory status epilepticus. Neurology (2003) 60:332-4. doi:10.1212/01.WNL.0000042783.86439.27

22. Synowiec AS, Yandora KA, Yenugadhati V, Valeriano JP, Schramke CJ, Kelly KM. The efficacy of topiramate in adult refractory status epilepticus: experience of a tertiary care center. Epilepsy Res (2012) 98:232-7. doi:10.1016/ j.eplepsyres.2011.09.017

23. Bensalam MK, Fakhoury TA. Topiramate and status epilepticus: report of three cases. Epilepsy Behav (2003) 4:757-60. doi:10.1016/j.yebeh.2003. 07.016

24. Streeter AJ, Stahle PL, Holland ML, Pritchard JF, Takacs AR. Pharmacokinetics and bioavailability of topiramate in the Beagle dog. Drug Metab Dispos (1995) 23(1):90-3.

25. Davis KA, Sturges BK, Vite CH, Ruedebusch V, Worrell G, Gardner AB, et al. A novel implanted device to wirelessly record and analyze continuous intracranial canine EEG. Epilepsy Res (2011) 96(1-2):116-22. doi:10.1016/ j.eplepsyres.2011.05.011

26. Coles LD, Patterson EE, Sheffield WD, Mavoori J, Higgins J, Michael B, et al. Feasibility study of a caregiver seizure alert system in canine epilepsy. Epilepsy Res (2013) 106(3):456-60. doi:10.1016/j.eplepsyres.2013.06.007

27. Marino SE, Birnbaum AK, Leppik IE, Conway JM, Musib LC, Brundage RC, et al. Steady-state carbamazepine pharmacokinetics following oral and stable-labeled intravenous administration in epilepsy patients: effects of race and sex. Clin Pharmacol Ther (2012) 91(3):483-8. doi:10.1038/clpt. 2011.251

28. Clark AM, Kriel RL, Leppik IE, White JR, Henry TR, Brundage RC, et al. Intravenous topiramate: safety and pharmacokinetics following a single dose in patients with epilepsy or migraines taking oral topiramate. Epilepsia (2013) 54(6):1106-11. doi:10.1111/epi.12165

29. Caldwell GW, Wu WN, Masucci JA, McKown LA, Gauthier D, Jones WJ, et al. Metabolism and excretion of the antiepileptic/antimigraine drug, topiramate in animals and humans. Eur J Drug Metab Pharmacokinet (2005) 30(3):151-64. doi:10.1007/BF03190614 
30. Muñana KR, Nettifee-Osborne JA, Papich MG. Effect of chronic administration of phenobarbital, or bromide, on pharmacokinetics of levetiracetam in dogs with epilepsy. J Vet Intern Med (2015) 29:614-9. doi:10.1111/ jvim. 12548

31. Patterson EE, Leppik IE, Coles LD, Podell M, Vite CH, Bush W, et al. Canine status epilepticus treated with fosphenytoin: a proof of principle study. Epilepsia (2015) 56(6):882-7. doi:10.1111/epi.12994

Conflict of Interest Statement: Drs. JC and IL are paid consultants for CuRx Pharmaceuticals. Dr. JC also receives payments from a licensing agreement between the University of Minnesota and Ligand Pharmaceuticals. We confirm that we have read the Journal's position on issues involved in ethical publication and affirm that this report is consistent with those guidelines. The other authors declare no conflict of interest.

Copyright (C) 2016 Vuu, Coles, Maglalang, Leppik, Worrell, Crepeau, Mishra, Cloyd and Patterson. This is an open-access article distributed under the terms of the Creative Commons Attribution License (CC BY). The use, distribution or reproduction in other forums is permitted, provided the original author(s) or licensor are credited and that the original publication in this journal is cited, in accordance with accepted academic practice. No use, distribution or reproduction is permitted which does not comply with these terms. 